\title{
Ensino de matéria e radiação no ensino médio com o auxílio de simuladores interativos ${ }^{+*}$
}

Antonio Augusto Soares ${ }^{1}$

Departamento de Física, Química e Matemática - DFQM

Universidade Federal de São Carlos - UFSCar

Sorocaba - SP

Letícia Estevão Moraes ${ }^{2}$

Franciéle Gonçalves Oliveira ${ }^{3}$

Graduandas - curso de Licenciatura em Física - UFSCar

Sorocaba - SP

\section{Resumo}

A física moderna e contemporânea como matéria de conhecimento no nível médio da educação básica tem sido defendida por diversos autores, mas apesar dos avanços tecnológicos e científicos, poucos estudos têm sido realizados na utilização de computadores e outras mídias no ensino de alguns temas dessa área. Neste trabalho utilizamos junto a duas turmas do ensino médio da rede pública algumas maneiras de fazer uso do computador e de simuladores interativos para uma melhor compreensão de alguns fenômenos físicos nessa área. Realizamos nossas análises a partir da perspectiva sócio-interativa de Vygotsky. Foram explorados os tópicos de espectroscopia, radioatividade e física nuclear usando as simulações interativas desenvolvidas pelo projeto Physics Educational Technology (PhET) da Universidade do Colorado. Concluímos que o uso de tais simuladores interativos auxilia no processo de ensino de tais tópicos, ajudando em sua compreensão e despertando o interesse dos estudantes para o tema.

\footnotetext{
${ }^{+}$Teaching matter and radiation in High School with the aid of interactive simulators

* Recebido: dezembro de 2014.

Aceito: junho de 2015.

1 E-mail: aasoares@ufscar.br

2 E-mail: leticia.ufscar@gmail.com

3 E-mail: franoliveira.ufscar@gmail.com
} 
Palavras-chave: Ensino de Física; Simuladores Interativos; Física Moderna e Contemporânea.

\begin{abstract}
The Modern and Contemporary Physics as a subject of knowledge in the high school education level has been defended by many authors. However, despite the technological and scientific advances, only few studies have been done regarding the use of computers and other media in teaching some topics in this area. In this work, which was performed in two high school classes from a public school, we applied a few ways to make use of computers and interactive simulators for a better understanding of some physical phenomena in this area. We conducted our analysis from the Vygotsky's social-interactive perspective. We explored the topics of Spectroscopy, Radioactivity and Nuclear Physics by using interactive simulations developed by the project Physics Education Technology (PhET) at the University of Colorado. We concluded that the use of this interactive simulators collaborates with the teaching of this topics, enhancing the student's understanding and awakening their interest on the subject.
\end{abstract}

Keywords: Physics teaching; Interactive simulators; Modern and Contemporary Physics.

\title{
I. Introdução
}

A sociedade moderna tem experimentado a cada dia novos avanços tecnológicos relacionados à tecnologia da informação. Computadores, tablets, smartphones, internet rápida, por exemplo, são elementos comuns a uma grande parcela da sociedade, principalmente entre os mais jovens. Tais tecnologias foram se incorporando ao dia a dia das pessoas e hoje estão presentes nos lares, lojas, carros, hospitais, supermercados, aeroportos etc. Como estudantes e professores, obviamente, fazem parte dessa sociedade, também estão expostos a essas tecnologias e ao grande volume de informação disponível na internet. Faz-se necessário, então, refletir sobre a utilização e a aplicação dessas novas ferramentas em sala de aula para auxiliar no processo de ensino-aprendizagem, inclusive no de física. Isso toma dimensões ainda maiores ao considerarmos que a física é a ciência cuja base fundamenta os princípios de funcionamento da grande maioria dessas tecnologias.

Wilson e Redish (1989) afirmam que mesmo com o advento e evolução do computador tenham revolucionado o modo como se desenvolvem as pesquisas científicas em física, o mesmo não alterou a forma de ensiná-la nas escolas. Apesar de esta contestação ter mais de duas décadas, sua validação ainda é fortemente presente nas escolas públicas 
brasileiras. Embora existam esforços no sentido de levar a tecnologia para as aulas de física, em um trabalho de revisão, Ataíde e Mesquita (2014) relatam que a distância entre a realidade dos mais jovens e aquela constatada no mundo escolar, no que tange ao uso e aplicação das tecnologias da informação, ainda é muito grande e pouco tem sido feito no sentido de se reduzir tal distância.

Os computadores e as tecnologias da informação devem, por exemplo, aparecer no processo de ensino de física como uma ferramenta no auxílio de demonstrações de experiências que eventualmente não possam ser realizadas no laboratório da escola, resoluções de problemas, produções de textos e hipertextos, aquisições de dados, simulações etc. Em outros termos, o computador, juntamente com seus aplicativos, pode ser inserido no ambiente escolar como uma complementação para o processo de ensino e como uma ferramenta para auxiliar o professor. Recursos tecnológicos têm sido utilizados para aprimorar a qualidade do processo ensinoaprendizagem, especialmente em física, onde os estudantes podem visualizar o que está sendo estudado e, assim, assimilar melhor os conteúdos. Segundo Macêdo e colaboradores (2012), atualmente o conhecimento segue em um caminho que leva a um processo aberto de aprendizagem, onde os envolvidos possuem, em boa medida, iguais oportunidades de acesso à informação. Nesse sentido, é de fundamental importância que o processo de ensinar física se alinhe à realidade das novas tecnologias da informação, incorporando-as em seus procedimentos em sala de aula e fora dela também.

\section{I.1 Simulações de fenômenos físicos no Ensino Médio}

No que tange ao uso das simulações computacionais, ao abordar simulações de experimentos em ótica, Souza e Nazaré (2012) salientam a importância deste tipo de recurso computacional como complementação da exposição teórica realizada pelo professor, levando a um ensino mais dinâmico e atrativo aos estudantes. Já no ensino de tópicos relativos à Física Moderna, Cardoso e Dickman (2012) aliaram simulação computacional e a Teoria da Aprendizagem Significativa de Piaget em uma proposta para o ensino do efeito fotoelétrico. Nesse trabalho concluiu-se que o uso do simulador computacional contribuiu, em muito, com o aprendizado do tema, pois os estudantes encontraram nessa ferramenta um elemento onde puderam testar suas hipóteses acerca do assunto. Heckler (2007) e Holec (2004), e seus respectivos colaboradores, também constataram que o uso do computador no processo de ensino de física tem caráter estimulador e motivacional aos estudantes.

As simulações contribuem de diversas formas dependendo do grau de interação entre o estudante e o software, dentre elas podemos citar: aumento da concentração dos estudantes nos experimentos, feedback para aperfeiçoamento do professor, geração e testes de hipóteses por parte dos estudantes, apresentação de uma versão simplificada da realidade proporcionando melhor compreensão de conceitos abstratos etc. Porém deve-se chamar a atenção para o fato de que em sistemas reais o tratamento de dados é mais complexo e que simuladores são 
representações e restrições de modelos que em alguns contextos tem validade e são razoáveis com a representação da natureza (VALENTE, 1999).

Como sugere as Diretrizes Curriculares Nacionais para o Ensino Médio (2013), o desenvolvimento científico que experimentamos atualmente deixa escolas e professores diante de uma realidade onde é fundamental colocar o estudante em situações de vida real de fazer e elaborar. As tecnologias da informação vêm, constantemente, modificando o comportamento das pessoas e isso precisa ser incorporado pelas escolas evitando, inclusive, o surgimento de uma nova forma de exclusão.

Macêdo e colaboradores (2014) observaram um bom volume de trabalhos apresentados no XIX Simpósio Nacional de Ensino de Física (SNEF), realizado em 2011, envolvendo o uso de tecnologias da informação aplicadas ao ensino de ciências (TIC's) sendo que a grande maioria desses trabalhos faz uso de simuladores computacionais. Apesar disso, esses mesmos autores concluem ser indispensável a realização e a divulgação de estudos que levem à disseminação dos processos e formas de utilização das TIC's no ensino de física.

No que concerne ao acesso aos simuladores e outros softwares relacionados ao tema, hoje em dia há uma vasta e gratuita oferta desses programas na internet. Um bom exemplo, e fonte dos simuladores que utilizamos neste trabalho, é o sítio do $\mathrm{PhET}^{4}$ da Universidade do Colorado. O PhET é um grupo que desenvolve, testa e disponibiliza on-line e gratuitamente vários simuladores e animações de fenômenos físicos e químicos. Esse grupo realiza pesquisas não somente relacionadas ao desenvolvimento, mas também ao uso desses softwares pelos estudantes, se preocupando como os estudantes em diferentes ambientes de aprendizagem se envolvem e interagem e qual a influência no aprendizado. Adams e colaboradores (2008), integrantes do grupo PhET, descrevem o processo de desenvolvimento da simulação, apontando os elementos que se mostram mais efetivos no processo de geração de engajamento por parte dos estudantes. Eles concluem que os simuladores computacionais desenvolvidos pelo grupo possuem alta eficácia no processo de engajamento sempre que as perguntas dos próprios estudantes levam à interação com o simulador.

Porém, o próprio grupo PhET alerta que é necessário ter cautela em relação ao uso de seus simuladores, pois objetivos operacionais de laboratório, envolvendo a manipulação e operação de aparelhos por exemplo, não podem ser abordados por simuladores. Segundo Carl Wieman - ganhador do prêmio Nobel em física de 2001 - e seus colaboradores (2010), por melhor que seja um simulador, este não consegue - e em nossa opinião nem deve - lograr sucesso automaticamente. Eles devem atuar, na verdade, como elementos de apoio a um currículo bem definido e delineado e a professores esforçados. Ainda segundo experiência relatada por esse grupo, o uso de simuladores leva a um grande número de perguntas espontâneas realizadas pelos estudantes.

\footnotetext{
${ }^{4}<$ http://phet.colorado.edu/pt_BR>.
} 


\section{I.2 Física Moderna e Contemporânea no Ensino Médio}

Em relação à Física Moderna e Contemporânea (FMC), abordar seus conceitos nas escolas no contexto da ciência e da tecnologia é de suma importância para que os estudantes possam lidar com questões que trazem consigo impactos sociais e ambientais. Portanto, é necessário repensar o currículo de modo a conduzir as aulas de física para abordagens que contribuam para uma formação abrangente dos estudantes, permitindo-lhes aprender conceitos básicos da ciência moderna e preparando-os para se posicionar de forma crítica sobre as questões do dia a dia (NARDI; MACHADO, 2007).

Em um trabalho de 2002, Medeiros e Medeiros já alertavam para o fato de que a FMC é apresentada de forma muito abstrata e de difícil compreensão, fazendo com que a matemática apareça como a ferramenta essencial no desenvolvimento da física. Deste modo, é necessário se desenvolver atividades voltadas para a parte conceitual do fenômeno físico, não se restringindo apenas às equações e às fórmulas matemáticas. Para Terrazzan (1994), o uso excessivo de ferramental matemático não se faz necessário na escola média, pois a abordagem da FMC - nesse nível do ensino básico - se justifica pelo seu conteúdo, pelo movimento da física e pela história da ciência moderna. É necessário que se incluam seus debates, discussões de experimentos e controvérsias da época, mostrando aos estudantes a ciência como construção humana, que não está pronta, acabada e nem é uma verdade absoluta.

Em relação ao ensino da FMC utilizando simuladores, em um artigo onde tratam do Efeito Fotoelétrico, Dickman e Cardoso (2012) também defendem que as simulações computacionais no ensino de física proporcionam maior interação entre os estudantes e o conteúdo trabalhado, levando ao surgimento de caminhos para a investigação e compreensão dos temas estudados.

Segundo Veit e Araújo (2005), ao fazer uso do computador, a tarefa de realizar as operações matemáticas fica transferida para o equipamento. Ainda segundo esses autores, isso deixa o indivíduo com mais tempo para avaliar o fenômeno físico, pensar nas hipóteses assumidas e nos possíveis desdobramentos do modelo em questão. Corroborando com essa discussão, Brockington e Pietrocola (2003) defendem que uma das principais características das simulações computacionais é a sua capacidade de trazer em si toda a matemática envolvida na explicação do fenômeno físico de que trata. Mesmo que o estudante ainda não seja capaz de lidar com tal matemática, utilizando os simuladores interativos ele consegue, além de compreender o fenômeno físico em questão, realizar e testar suas hipóteses acerca desse fenômeno. Ou seja, o professor, ao fazer uso de simuladores em suas aulas, consegue a ligação entre o pensar sobre o fenômeno e sua "utilização prática", procedimento fundamental para a significação do conteúdo abordado. Portanto o computador, juntamente com seus aplicativos, deve ser encarado como mais uma ferramenta auxiliar no processo de ensino-aprendizagem, ajudando professores e estudantes no processo de aprendizagem da FMC.

$\mathrm{O}$ ensino de FMC pode se beneficiar das novas tecnologias computacionais, principalmente em situações onde o grau de complexidade do tema estudado é maior. Outro 
ponto muito importante refere-se à parte experimental. A maioria das experiências da FMC não é realizada em laboratórios escolares devido às deficiências de infraestrutura. Neste sentido, torna-se fundamental que tais tópicos sejam apresentados e trabalhados utilizando simulações computacionais e problematizados com abordagens CTSA (Ciência, Tecnologia, Sociedade e Ambiente).

Inspirados em um trabalho de Ostermann e Moreira (2000) e pautados pela perspectiva de Vygotsky, neste trabalho procuramos conciliar o uso da tecnologia da informação com a necessidade de abordagens da FMC no Ensino Médio (EM). Propomos e exploramos o uso de materiais didáticos digitais, neste caso simuladores interativos e animações, relacionados ao tema e que são de fácil acesso tanto para os professores assim como para os estudantes. Realizamos um estudo de caso com um grupo de estudantes do $3^{\circ}$ ano do EM, em uma escola do interior do estado de São Paulo. Utilizamos simuladores interativos e animações como coadjuvantes no processo ensino-aprendizagem de FMC, empregando-os tanto para uma abordagem fenomenológica inicial acerca de cada um dos temas trabalhados, assim como para o aprofundamento e contextualização dos mesmos. Outro ponto que procuramos observar foi se tais ferramentas contribuem no despertar do interesse dos estudantes pelos temas em questão, interesse este que tem larga implicação na efetivação do processo de interação dos estudantes com o docente. Trabalhamos aqui com tópicos relacionados à espectroscopia, radioatividade e física nuclear. Cabe aqui mencionar que nossa abordagem Vygotskiana não tem a intenção, e nem o faz, de abordar essa complexa teoria em sua completude.

\section{Referencial teórico}

Para Lev Vygotsky (1991), em sua teoria sócio-interacionista, é na interação entre pessoas que se constrói o conhecimento, e a mediação é essencial no processo ensinoaprendizagem. Para se entender o processo de desenvolvimento cognitivo, é fundamental que haja relação com o contexto social, histórico e cultural.

Neste trabalho, pretendemos avaliar o alinhamento do uso de simuladores computacionais com o desenvolvimento da Zona de Desenvolvimento Proximal (ZDP) proposta na teoria de Vygotsky. A ZDP representa a separação entre o nível de desenvolvimento atual, medido pela resolução independente de problemas, e o nível de desenvolvimento potencial, medido pela resolução de problemas sob a orientação ou em colaboração com outras pessoas que já apresentam maior capacidade em um dado tema.

Nesse sentindo, a ZDP é o espaço onde, com a ajuda e interação com outra pessoa, um determinado indivíduo consegue realizar uma dada tarefa em um nível e de forma que não o faria por conta própria. Aqui é importante esclarecer que não se trata de um espaço físico, mas relacionado à capacidade de aquisição de conhecimento. É um espaço teórico que surge no processo de interação entre o estudante e seu professor que envolve as técnicas, recursos e suportes utilizados pelo docente. Nesse sentido, para um dado estudante, não existe uma única 
ZDP, mas sim uma miríade delas nas mais diversas áreas do conhecimento. E é justamente em relação à interação, elemento central na teoria de Vygotsky e fundamental no desenvolvimento da ZDP, que focamos. Analisamos a eficácia do uso de simuladores virtuais em viabilizar e potencializar a interação entre os estudantes e o docente.

Além disso, para Pereira e Junior (2014), uma simulação computacional, dentre outras inovações, possui o potencial de levar a mudanças significativas na forma de realização de algumas atividades mentais por parte dos estudantes, atividades estas que eventualmente não poderiam ser realizadas sem tal ferramental. Ainda segundo esses autores, isso nada mais é do que uma das implicações da teoria de Vygostsky no ensino de Física.

Desejamos, neste trabalho, verificar se o uso do computador e das simulações computacionais como instrumentos de aprendizagem contribuem no processo de apropriação da cultura e do conhecimento, e se colaboram com o docente no processo de mediação uma vez que se relacionam ao contexto social e cultural do estudante dos dias de hoje.

\section{Metodologia}

Neste trabalho realizamos um estudo de caso descritivo abordando três diferentes temas relacionados à FMC, a saber, espectroscopia, radioatividade e física nuclear. Em cada uma dessas abordagens utilizamos simuladores virtuais desenvolvidos pelo grupo PhET e relacionados a cada um dos temas de aula.

Esse estudo ocorreu junto a duas turmas do $3^{\circ}$ ano do ensino médio de uma escola da rede pública do interior de São Paulo. Os temas acima mencionados foram abordados separadamente, isto é, um em cada duas aulas de 50 minutos totalizando, em cada tema, 100 minutos. Durante cada uma dessas aulas procuramos observar e avaliar o envolvimento e o desenvolvimento dos estudantes em cada um dos temas abordados.

$\mathrm{Na}$ perspectiva da teoria sócio-interacionista de Vygotsky, iniciamos todas as abordagens junto aos estudantes fazendo com que os mesmos expressassem seus conhecimentos e suas concepções que eventualmente possuíssem acerca do assunto abordado, até mesmo em relação à terminologia empregada. Considerando a proposta de Vygotsky de que a aprendizagem nunca parte do zero e que esta apresenta uma "pré-história", esses momentos tinham como objetivo nos colocar a par da preparação prévia dos estudantes, assim como evidenciar aos próprios estudantes aquilo que já traziam consigo de aulas e experiências passadas, colaborando assim com o desenvolvimento do aprendizado.

Ao utilizarmos junto aos estudantes os simuladores virtuais, tomamos sempre uma postura tal que garantisse a máxima e efetiva interação dos estudantes conosco, professores, e com o problema em discussão, procurando evitar um comportamento passivo dos estudantes frente ao que ensinávamos. Nesse sentido, procuramos respeitar a teoria de Vygotsky, garantindo uma postura de mediador do conhecimento a ser aprendido pelos estudantes.

$\mathrm{O}$ primeiro tema tratado foi espectroscopia. Iniciamos nossa abordagem com a apresentação teórica do tema e também usando um material lúdico sobre as linhas espectrais. 
Tal material é constituído do espectro de emissão de diferentes espécies atômicas (parte visível) impresso em transparências e teve como objetivo familiarizá-los com o tema. Em seguida foi apresentado o simulador "Lâmpadas de neônio e outras lâmpadas de descarga", em sua versão $1.13^{5}$ que permite estudar, dentre outros, o espectro de emissão dos átomos de neônio, possibilitando compreender os decaimentos dos níveis de energia e, assim, visualizar como são formadas as linhas espectrais.

A Fig. 1 mostra uma tela desse simulador em operação. Podemos ver que no canto superior direito é possível escolher o átomo para o qual se deseja obter o padrão das linhas de emissão (espectro de emissão). No centro superior do simulador encontra-se a representação de uma pilha que pode ter sua voltagem variada pelo usuário. Isso permite mostrar aos estudantes que quanto mais energia é aplicada ao sistema, maior será a energia dos decaimentos entre os níveis energéticos do átomo em estudo. Isto é, quanto maior a voltagem aplicada, maior é a excitação dos átomos. As linhas de emissão podem ser visualizadas na parte inferior da Fig. 1.

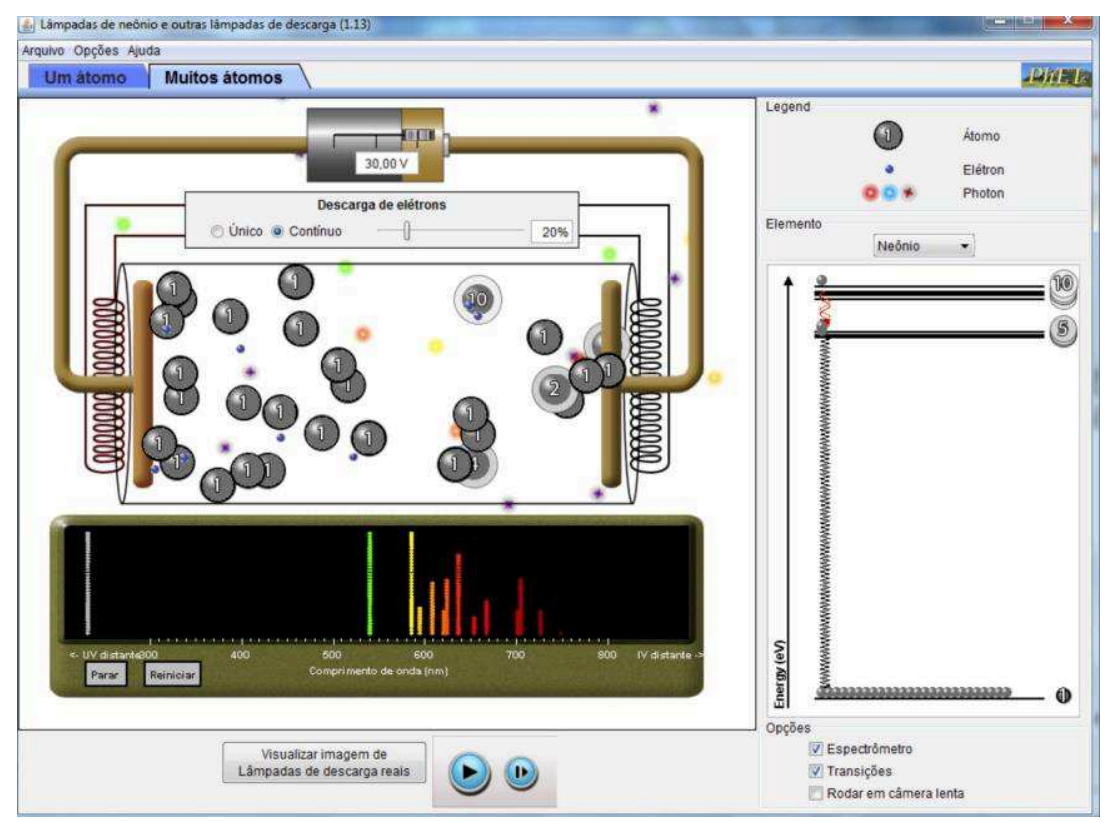

Fig. 1 - Tela do simulador "Lâmpadas de neônio e outras lâmpadas de descarga" mostrando a obtenção do espectro de emissão para os átomos de neônio.

Buscando relacionar os conceitos estudados com o cotidiano desses estudantes, foi discutido sobre a aplicação da espectroscopia em estudos ambientais citando o uso da espectroscopia na análise de amostras de poluentes emitidos pelas chaminés de fábricas. Também a título de exemplo, foi discutido o uso da espectroscopia na astronomia.

Demos sequência aos trabalhos abordando o tema radioatividade. Iniciamos a explanação sobre esse tema explorando o conceito de meia-vida e ensinando que uma das

\footnotetext{
${ }^{5}$ Disponível em: <http://phet.colorado.edu/pt_BR/simulation/discharge-lamps>. Acesso em: 15 mai. 2014.
} 
técnicas utilizadas para determinar a idade de objetos antigos é a datação radiométrica, utilizando o carbono-14 e urânio-238.

Em seguida apresentamos os conceitos de estabilidade nuclear e os tipos de decaimentos (alfa, beta e gama) que levam à emissão de radiação. De forma sucinta, porém sem perder a generalidade, foram explicadas as leis de cada decaimento, destacando que podem ser expressas matematicamente pela seguinte equação:

$$
N(t)=N_{0} \cdot e^{-\gamma t} .
$$

Na equação (1), $N(t)$ é o número de núcleos radioativos de uma dada amostra em um instante de tempo $t, N_{0}$ é o número de núcleos radioativos no instante inicial, $e$ é a base do logaritmo natural e $\gamma$ é a constante de decaimento que se relaciona com o tempo de meia-vida $\left(T_{1 / 2}\right)$ através de:

$$
T_{1 / 2}=\frac{\ln (2)}{\gamma}
$$

Embora tenhamos apresentado as equações relacionadas ao fenômeno em questão, nos limitamos apenas a isso no que diz respeito à matemática e primamos pela discussão do fenômeno em si, delegando o restante da matemática ao simulador que, além de realizar os cálculos necessários, apresentava na tela do computador os gráficos relacionados à equação (1).

Para facilitar a compreensão do conteúdo, utilizou-se um jogo lúdico chamado "dominó radioativo" para as séries do urânio e do tório que tinha por objetivo mostrar o fato de que dificilmente o núcleo se estabiliza com apenas uma transformação, e que ocorre uma sequência de outras transformações que levam a uma série. Isso permitiu discutir os estágios intermediários nessa sequência de transformações que levam às famílias radioativas. Essa primeira atividade teve como objetivo levar ao conhecimento dos estudantes as transformações nucleares que dão origem à radioatividade e compreender a diferença entre os decaimentos alfa e beta, presentes nas famílias radioativas.

Como exemplos para contextualização e aplicação das técnicas de datação radioativa foram utilizados o Parque Nacional Serra da Capivara, localizado no sudeste do Piauí, a Caverna de Chauvet, no sul da França, que é o sítio arqueológico mais importante do mundo, o dente de dinossauro carnívoro que foi encontrado por paleontólogos no estado de Minas Gerais, entre outros.

Feito isso, para aprofundar o conceito de meia-vida e discutir a natureza aleatória dos decaimentos dos núcleos, utilizamos o simulador "Jogo da Datação Radioativa" em sua versão 3.276. A Fig. 2 mostra uma das telas desse simulador.

\footnotetext{
6 Disponível em: <http://phet.colorado.edu/pt_BR/simulation/radioactive-dating-game>. Acesso em: 15 mai. 2014.
} 


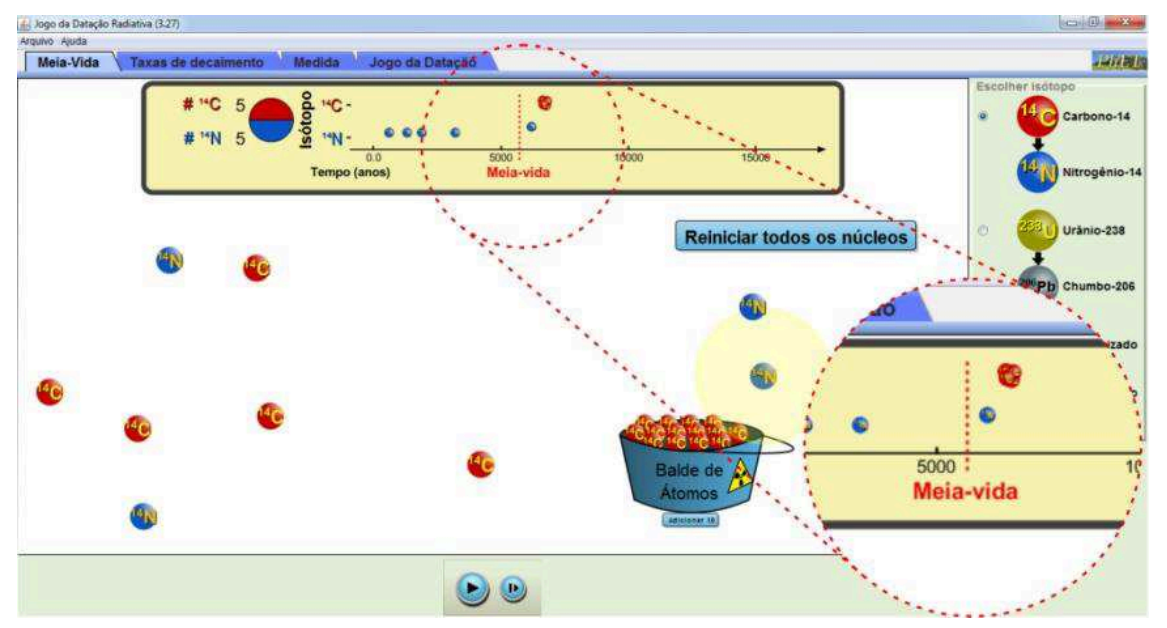

Fig. 2- Tela do simulador "Jogo da Datação Radioativa" mostrando a aba "MeiaVida". No topo da tela pode ser observada a meia-vida (em anos) dos isótopos radioativos. No canto inferior direito é mostrada uma ampliação de parte da imagem principal, dando maior destaque à meia-vida.

Utilizando a aba "Medida" desse mesmo simulador, cuja tela é mostrada na figura 3, apresentou-se aos estudantes o princípio de funcionamento da datação radiométrica. Isso foi possível por que esse simulador permite escolher o objeto a ser datado (árvore ou rocha vulcânica) e para cada um destes objetos é possível escolher um tipo de elemento radioativo apropriado para ser usado em sua datação. Devido aos diferentes tempos de meia-vida dos átomos envolvidos, para a árvore é utilizado o carbono-14 enquanto que para a rocha vulcânica é utilizado o urânio-238.

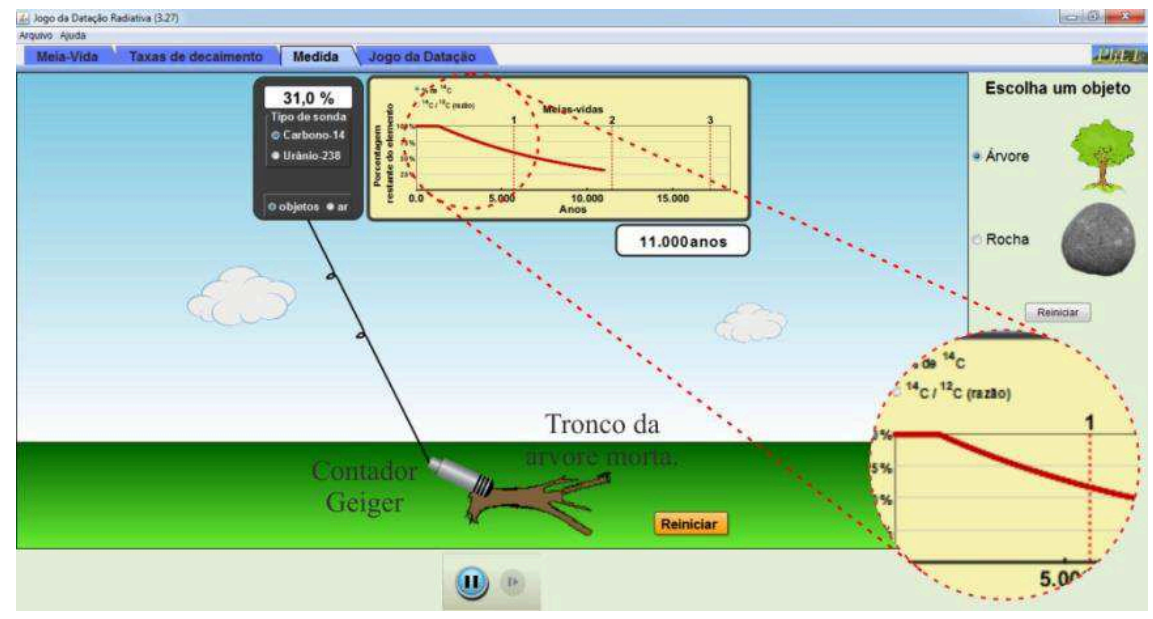

Fig. 3 - Simulador "Jogo da Datação Radioativa" mostrando a aba "Medida". É possível escolher entre uma árvore e uma rocha vulcânica e o respectivo isótopo necessário à sua datação. No canto inferior direito é mostrada uma ampliação do gráfico do topo da figura principal. 
Ainda em relação à Fig. 3, a ampliação apresentada no canto inferior direito mostra parte do gráfico do decaimento, neste caso, do carbono-14. Esse gráfico, que traz consigo boa parte da matemática relacionada ao fenômeno, foi utilizado para abordar dois aspectos muito importantes relacionados ao tema. O primeiro deles se refere ao decaimento exponencial, relativo à forma do gráfico após a árvore morrer e que pode ser relacionado com a expressão matemática inicialmente apresentada aos estudantes (equação (1)). O outro aspecto foi abordado a partir do trecho constante do gráfico. Tal trecho refere-se ao tempo em que a árvore ainda era viva e permite mostrar aos estudantes que, nesse período, a concentração de carbono14 mantém-se fixa, isto é, constante e que somente após a morte da árvore é que a concentração começa a decair exponencialmente.

Em seguida, para fecharmos essa abordagem e atingirmos nossos objetivos em relação à contextualização e aplicação do fenômeno físico apresentado, utilizamos a aba "Jogo da Datação" cuja tela é mostrada na Fig. 4. Nesse jogo, ao se aproximar o contador Geiger de um dos objetos localizados na parte inferior da tela, na parte superior é mostrado o percentual do elemento radioativo ainda presente na amostra possibilitando, assim, calcular a idade do objeto escolhido. Nessa tela também é mostrado um gráfico, similar àquele da Fig. 3, que possibilita visualizar a taxa de decaimento radioativo, permitindo contextualizar os conceitos trabalhados, problematizar situações e reforçar as discussões relativas à função matemática empregada na modelagem do fenômeno físico (equação (1)).

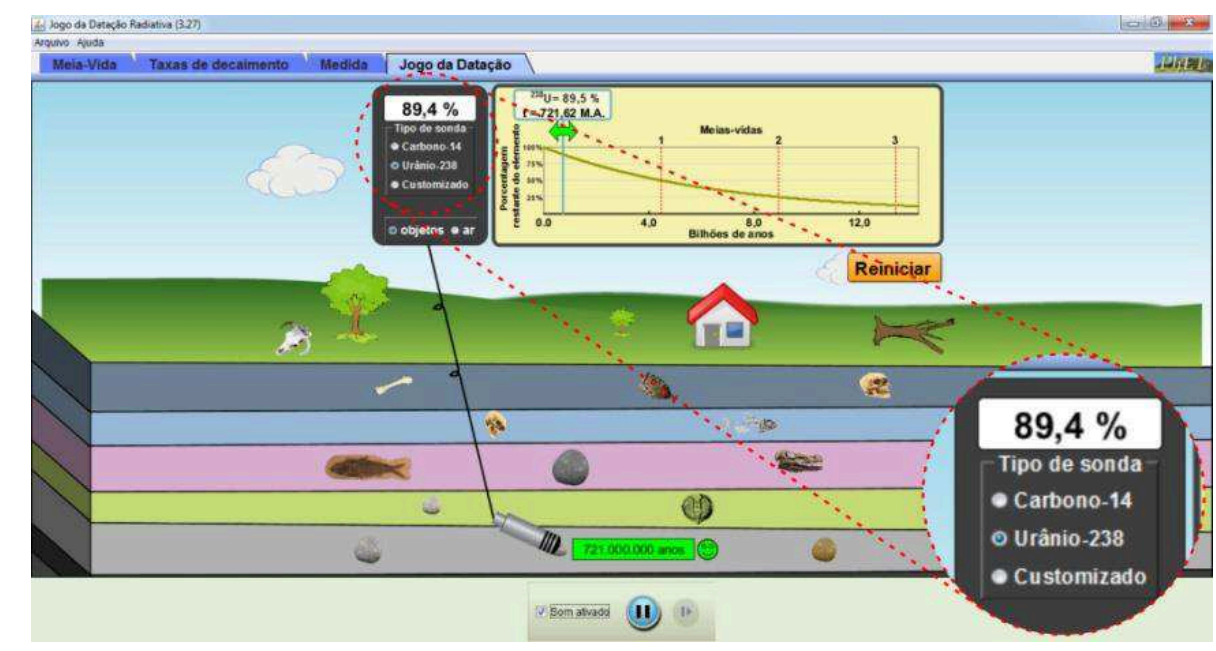

Fig. 4 - Tela do simulador "Jogo da Datação Radioativa" mostrando como a datação radiométrica funciona e como diferentes elementos são usados para datar diferentes objetos. No canto inferior direito é mostrada uma ampliação da imagem principal. 
No encontro posterior, o último deles, foram trabalhados os conteúdos relacionados à física nuclear, mais precisamente a fissão nuclear. Nesse momento utilizamos o simulador "Fissão Nuclear", versão 3.27 .

Inicialmente abordamos a diferença entre o urânio-235 e o urânio-238 em relação à propriedade da fissão de seus núcleos. Para isso foi utilizada a aba "Reação em Cadeia" mostrada na figura 5 onde é possível escolher a quantidade dos elementos urânio-235 e urânio238 em estudo. Este simulador também apresenta a opção de se utilizar uma câmara de contenção, circunferência em preto na Fig. 5, que permite ao professor abordar e discutir assuntos relacionados aos acidentes e à segurança em usinas nucleares, por exemplo.

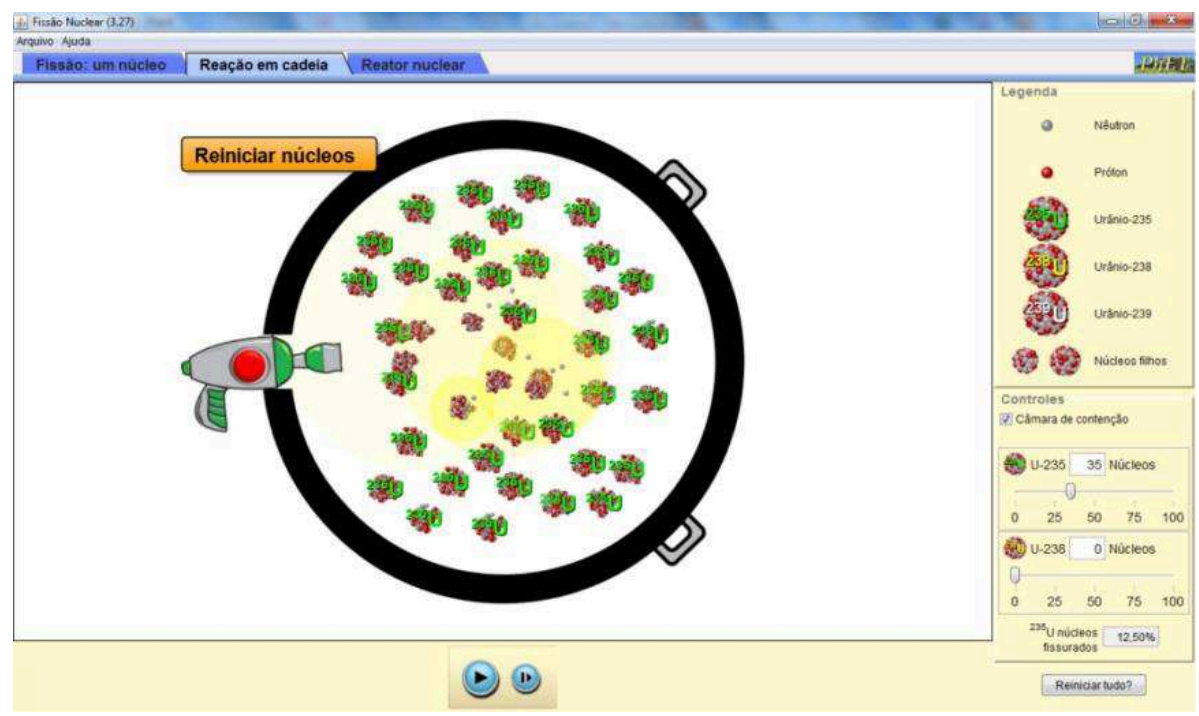

Fig. 5 - Tela do simulador "Fissão Nuclear" mostrando o processo de reação em cadeia em andamento com diversos núcleos de urânio-235 sendo atingidos por nêutrons e sofrendo decaimento para seus átomos filhos.

Ao disparar o nêutron, utilizando a arma de nêutrons também mostrada na Fig. 5, sobre uma coleção constituída apenas de núcleos de urânio-235 visualiza-se uma reação em cadeia, onde o elemento físsil decai em dois elementos menos radiativos e há a liberação de três novos nêutrons. Tal procedimento permite mostrar aos estudantes como um único nêutron de baixa energia pode dar origem a uma reação em cadeia. Por outro lado, ao disparar o nêutron sobre núcleos de urânio-238 nada acontece, pois sua fissão só ocorre com nêutrons de alta energia. Nessa situação, o urânio-238 apenas absorve o nêutron e se transforma em urânio-239.

Para demonstrar uma aplicação desse fenômeno, utilizamos um vídeo intitulado "Energia Nuclear - Como Funciona" que mostra como acontece a produção de energia nuclear

\footnotetext{
${ }^{7}$ Disponível em: <http://phet.colorado.edu/pt_BR/simulation/nuclear-fission>. Acesso em: 15 mai. 2014.

${ }^{8}$ Disponível em: <https://www.youtube.com/watch?v=nCmxLRUaR4w>. Acesso em: 20 mai. 2014.
} 
no Brasil. Como complementação a esse vídeo e para uma melhor visualização do processo de produção de energia elétrica em uma usina nuclear, também foi apresentada uma animação ${ }^{9}$ cuja uma das telas é apresentada na Fig. 6.

Além disso, utilizando a aba "Reator Nuclear" do simulador "Fissão Nuclear", foi mostrada uma representação do interior do reator e como as barras de controle podem ser usadas para retardar as reações. Isso permitiu aos estudantes visualizar a função da água de refrigeração, necessária no processo de controle da temperatura e da pressão em uma usina nuclear.

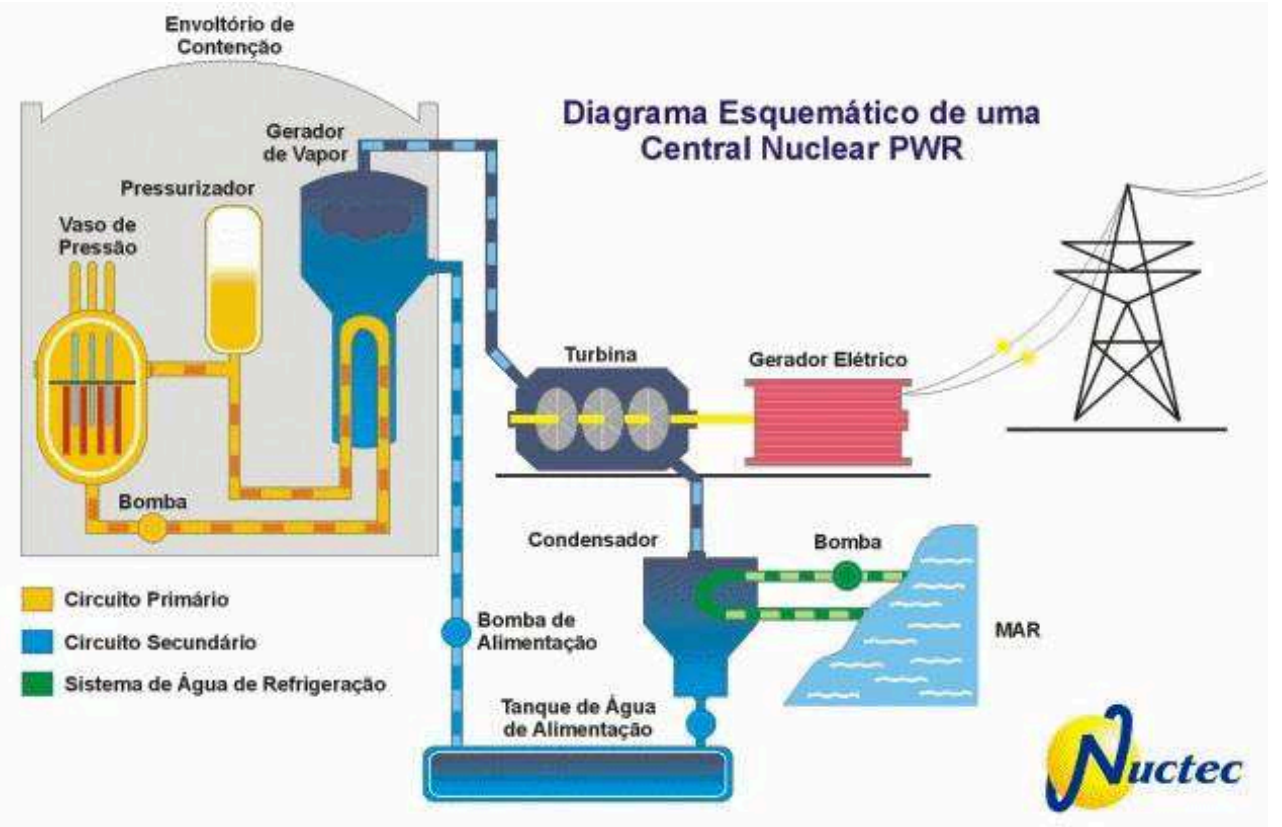

Fig. 6 - Tela da animação utilizada para mostrar o princípio de funcionamento de uma usina nuclear.

Como o tema tratado levou ao surgimento de várias inquietações, foi possível discutir as vantagens e as desvantagens do uso da energia nuclear. Por um lado foi apresentado o vídeo a "História da Bomba Atômica" e a música Rosa de Hiroshima, que é um poema de Vinícius de Moraes e foi regravada por Ney Matogrosso. Por outro lado, utilizando exemplos, foram mostrados os benefícios dessa energia e como ela está presente em nossas vidas.

Em todas as abordagens permitimos ampla manifestação dos estudantes, deixando que os mesmos levantassem e avaliassem suas próprias hipóteses sobre os fenômenos abordados. Isso permitiu grande interação verbal entre os estudantes e o professor, interação esta promovida pelo dinamismo da aula que foi alcançado devido ao uso dos simuladores.

\footnotetext{
${ }^{9}$ Disponível em: <http://www.nuctec.com.br/educacional/funcionam.html>. Acesso em: 20 mai. 2014.
} 


\section{Avaliação dos resultados}

Ao abordar o tema espectroscopia percebeu-se o despertar de grande interação dos estudantes com o docente durante a atividade. Uma das observações levantadas pelos estudantes foi a de que o uso do simulador "Lâmpada de neônio e outras lâmpadas de descarga" contribuiu para ajudar a visualizar algo tão complexo. Isso ficou evidente quando um dos estudantes comentou que "é meio complexo de entender como o átomo funciona, isso foge da minha cabeça (sic)".

Esse simulador permitiu abordar junto aos estudantes uma técnica muito importante em diversas áreas de pesquisas científicas que é a espectroscopia. Devido ao uso desse simulador na exposição do tópico, foi possível atrair grande atenção dos estudantes para a aula, permitindo ampla discussão e argumentação sobre as aplicações da técnica e suas relações com o dia a dia dos mesmos. Dado o dinamismo proporcionado pelo simulador, também foi possível tratar de temas histórico-culturais relacionados com o tópico em questão como, por exemplo, o contexto histórico na época em que Niels Bohr desenvolveu seu modelo atômico.

A utilização do simulador "Jogo da Datação Radioativa" contribuiu para que os estudantes visualizassem, de maneira relativamente simples e efetiva, como ocorre o processo de decaimento radioativo e que a meia-vida é o tempo para que metade de uma amostra radioativa decaia do átomo pai para o átomo filho. Além disso, o fato deste simulador apresentar o gráfico do decaimento radioativo nas abas "Medidas" e "Jogo da Datação" permitiu fazer uma relação direta com a função matemática do modelo de decaimento. A importância disso está no fato de que pudemos abordar a matemática de forma não excessiva, mas sem abandoná-la, como defendido em Terrazzan (1994), Medeiros e Medeiros (2002), Brockington e Pietrocola (2003). Foi possível inclusive, embora de maneira breve, tratar do termo modelagem matemática.

A aba "Medida" desse mesmo simulador, mostrada na Fig. 3, contribuiu para que os estudantes compreendessem que para fazer a datação de objetos antigos com diferentes idades se utiliza o decaimento radioativo de diferentes espécies atômicas. Rochas vulcânicas apresentam idades superiores a milhões ou até mesmo bilhões de anos, já uma árvore tem idade inferior a milhões de anos. Com a utilização da simulação os estudantes conseguiram concluir que para a rocha vulcânica faz-se necessário o uso da datação por urânio-238, enquanto que para uma árvore o ideal é usar o carbono-14 e que isso se deve aos tempos de meias-vidas dos elementos. Aqui foi possível perceber uma evolução dos estudantes no que se refere aos processos de medida de tempo, neste caso relacionado à idade de fósseis.

Em relação à fissão nuclear, nas discussões e conversas com os estudantes dessas turmas, estes demonstraram ter compreendido sobre a ideia de elemento físsil. Com o uso do simulador "Fissão Nuclear", na aba "Fissão: um núcleo", os estudantes conseguiram facilmente visualizar que no processo de fissão há a liberação de dois elementos secundários, os átomos filhos, e três nêutrons. Já na apresentação e discussão da reação em cadeia usando a aba "Reação em Cadeia", foi perguntado aos estudantes o que eles imaginavam que deveria ocorrer na liberação de três nêutrons em uma reação na qual existem mais elementos radioativos físseis 
nas proximidades. Os estudantes não haviam percebido ainda que os três nêutrons que eram resultado do processo de fissão do primeiro núcleo apresentavam exatamente as mesmas características do nêutron inicial. Após a utilização do simulador "Fissão Nuclear" para apresentar o processo de reação em cadeia, os estudantes se surpreenderam com a quantidade de reações e que outras ocorriam como resultado de uma anterior, facilitando assim a compreensão de tal processo.

Usando a aba do simulador "Reator Nuclear" e a animação da usina nuclear (Fig. 6), foi exposta a ideia principal da importância do sistema secundário de refrigeração para não ocasionar o superaquecimento do reator e, neste momento os estudantes abstraíram sobre este conceito, relacionando-o com o acidente nuclear de Fukushima, no Japão, ocorrido em 2011. Ficou evidente uma maior interação dos estudantes neste último tópico, no qual eles defendiam a concepção de que este é um tema de muita importância e bastante repercutido na imprensa. Um desses estudantes citou que "a tv fala desses assuntos, mas antes eu não tinha nem ideia do que era. Agora eu posso argumentar e entender (sic)".

Os estudantes dessas turmas, de forma geral, bem como o docente responsável pela disciplina de física, nos relataram que o uso dos simuladores, além de possibilitar uma melhor visualização dos processos, incentivou os estudantes a terem mais interesse pelo tema, levandoos a fazerem mais questionamentos sobre o assunto e, assim, viabilizando a interação com o docente. Também mencionaram que seria interessante o seu uso em outras disciplinas.

Observamos que ao usar os recursos computacionais na apresentação e discussão dos temas abordados neste trabalho conseguimos promover vários momentos de interação que, como afirma Vygotsky, permite mediar os conhecimentos trazidos pelos estudantes com as novas informações a serem adquiridas, fazendo com que ele não crie uma visão distorcida do fenômeno. O computador, nessa tarefa, mostrou-se um excelente instrumento para o ensino, auxiliando na construção de conceitos e proporcionando uma maior interação e participação dos estudantes.

Ao permitir a abordagem de um tema de tal complexidade e conhecida relevância no cenário tecnológico atual, os simuladores empregados neste estudo contribuíram para que os estudantes se envolvessem de forma mais profunda com os temas, permitindo uma evidente interação com o docente. Nitidamente, o uso desses simuladores levou a uma evolução dos estudantes através das respectivas ZDP's, colocando-os, um a um, em uma posição tal que os permitiu compor análises e comentários refinados acerca dos temas em questão. Portanto, nas duas turmas participantes deste nosso estudo, os temas relacionados à FMC abordados numa perspectiva da teoria sócio-interativa de Vygotsky se mostraram interessantes aos olhos dos estudantes, reforçando a participação e o envolvimento dos mesmos. Além disso, ao permitir que os estudantes tenham acesso aos conhecimentos relacionados à FMC, conhecimentos estes contemporâneos e amplamente presentes em nosso dia a dia, é viabilizar o real contato desses estudantes com a sociedade e a cultura contemporâneas, garantindo uma relação dialética do indivíduo com o mundo que o circunda e do qual ele faz parte e pode intervir. 
$\mathrm{O}$ uso de simuladores interativos se mostrou, em nossas abordagens junto às duas turmas do $3^{\circ}$ ano do EM, como elementos facilitadores da atividade docente quando olhamos da perspectiva da teoria de Vygotsky por permitir uma postura mais ativa (e efetiva) do professor no processo de mediação.

Uma vez que fizemos um uso detalhado dos simuladores abordados neste trabalho, também julgamos pertinente apresentar nossas observações sobre pontos onde tais simuladores apresentam alguma deficiência. A tabela 1 apresenta, de forma resumida, tais observações.

Tabela 1: Resumo dos pontos onde observamos deficiência em alguns dos simuladores interativos utilizados no ensino dos tópicos de FMC abordados neste trabalho.

\begin{tabular}{|c|c|c|}
\hline Software & Problemas observados & Implicações \\
\hline \multirow[t]{2}{*}{$\begin{array}{l}\text { Lâmpadas de neônio e } \\
\text { outras lâmpadas de descarga }\end{array}$} & $\begin{array}{l}\text { A escala do eixo dos } \\
\text { comprimentos de onda do } \\
\text { espectro na parte inferior da } \\
\text { figura } 1 \text { é fixa e incompleta, } \\
\text { indo apenas de } 300 \text { nm a } 400 \\
\text { nm. }\end{array}$ & $\begin{array}{l}\text { Não permite mostrar } \\
\text { eventuais linhas no UV e IV } \\
\text { distantes. Não permite } \\
\text { estimar o comprimento de } \\
\text { onda, por exemplo, da linha } \\
\text { espectral mais à esquerda na } \\
\text { figura 1. }\end{array}$ \\
\hline & $\begin{array}{l}\text { A visualização de lâmpadas } \\
\text { de descarga reais apresenta } \\
\text { todo o texto em inglês. }\end{array}$ & $\begin{array}{l}\text { Pensamos que num primeiro } \\
\text { contato dos estudantes com } \\
\text { novos temas, a língua a ser } \\
\text { utilizada deva ser o } \\
\text { português. }\end{array}$ \\
\hline \multirow{2}{*}{ Jogo da Datação Radioativa } & $\begin{array}{l}\text { Na aba "Jogo da Datação" } \\
\text { mostrada na figura 4, é } \\
\text { utilizada como unidade de } \\
\text { tempo "M.A." ou "B.A." } \\
\text { para se referir a "milhões de } \\
\text { anos" e "bilhões de anos", } \\
\text { respectivamente. }\end{array}$ & $\begin{array}{l}\text { Deveria ser utilizada, por } \\
\text { exemplo, a unidade Ma } \\
\text { (mega annum) ou, como } \\
\text { preferimos, a notação } \\
\text { científica e unidades do } \\
\text { sistema internacional. }\end{array}$ \\
\hline & $\begin{array}{l}\text { Na aba "Jogo da Datação" } \\
\text { mostrada na figura } 4 \text {, ao se } \\
\text { aproximar o contador Geiger } \\
\text { de alguns objetos, obtém-se } \\
0,0 \% \text { de concentração do } \\
\text { isótopo radioativo em } \\
\text { questão. }\end{array}$ & $\begin{array}{l}\text { Uma vez que nem todos os } \\
\text { objetos podem ser datados, } \\
\text { pode causar confusão aos } \\
\text { estudantes. }\end{array}$ \\
\hline
\end{tabular}

Apesar das deficiências apontadas na tabela 1, estando o professor atento a elas, os simuladores se mostraram um efetivo elemento auxiliar no processo ensino-aprendizagem dos tópicos de FMC aqui abordados. 


\section{Conclusões}

No estudo aqui apresentado, fizemos uso de simuladores computacionais para auxiliar no processo de ensino de tópicos de FMC observando o cunho facilitador em relação à perspectiva da teoria de Vygotsky.

Esses simuladores permitem preencher uma lacuna fenomenológica que geralmente dificulta o processo de apresentação e início de discussão de alguns temas da física, principalmente aqueles relacionados à FMC.

A utilização de simuladores no ensino dos temas aqui abordados também contribuiu para que os estudantes entendessem melhor os conteúdos apresentados, pois permitiu visualizar modelos de conceitos abstratos em tempo real, trabalhar com conceitos prévios, com hipóteses e até mesmo com concepções alternativas. Verificou-se ainda que o uso de simuladores, além de possibilitar o conhecimento e o aprofundamento dos conceitos, ajuda em uma melhor interpretação dos fenômenos físicos. O uso do computador demonstrou eficácia na melhoria da prática docente, seja por permitir introduzir novos tópicos, refletir ou revisar conteúdos ou, até mesmo, construir conceitos.

O uso do computador e simuladores interativos nas duas turmas do EM envolvidas neste trabalho, no ensino dos temas aqui abordados, se caracterizou como uma excelente ferramenta no auxílio ao desenvolvimento dos estudantes através da ZDP, pois fomentou e potencializou a interação entre os estudantes e o docente nas discussões e análises dos modelos e teorias. Os simuladores aqui avaliados se mostraram capazes de ajudar a promover um ambiente de conversa, discussão e reflexão sobre tais temas que, uns mais outros menos, estão diretamente relacionados ao dia a dia dos estudantes. Porém, por se tratar de mais uma ferramenta a serviço do ensino de física, o simulador interativo deve ser utilizado com cautela, sempre procurando pela melhor forma de inseri-lo na abordagem e no tratamento dos temas do currículo de física para o EM.

Acreditamos que o uso de tecnologias modernas, como aquelas relacionadas às TIC's, leva a uma melhora na relação do estudante contemporâneo com o outro, neste caso o professor, facilitando a interação também por que se passa a "conversar em uma mesma língua", obviamente, dentro de um contexto de aprendizado. O uso dos simuladores no ensino dos tópicos de física abordados neste trabalho constitui-se, de certa forma, em um meio de colocar o estudante em atividade prática, permitindo uma melhor análise do funcionamento do indivíduo durante o processo de aprendizado de física.

No desenvolver deste trabalho, também percebemos a evidente necessidade de uma maior exploração de temas relacionados à FMC no EM. Acreditamos que a continuidade desses estudos, a partir de questões propostas e da interação presenciada entre os estudantes e os simuladores, possa auxiliar na complementação do estudo realizado, possibilitando um aprofundamento sobre os aspectos metodológicos, quais são as implicações e os impactos da socialização do conhecimento científico para a formação de cidadãos cientificamente letrados, conscientes e atuantes. 


\section{Bibliografia}

ADAMS, W. K. et al. A Study of Educational Simulations Part I - Engagement and Learning. Journal of Interactive Learning Research, v. 19, p. 397-419, jul. 2008.

ATAÍDE, J. F.; MESQUITA, N. A. S. O Arborescer das TIC na Educação: da raiz aos ramos mais recentes. Revista Brasileira de Ensino de Ciência e Tecnologia, v. 7, n. 1, p. 82-106, 2014.

BRASIL, M. D. E. Diretrizes Curriculares Nacionais Gerais da Educação Básica. Brasília: MEC, 2013.

BROCKINGTON, G.; PIETROCOLA, M. Recursos computacionais disponíveis na internet para o ensino de Física Moderna e Contemporânea. In: ENCONTRO DE PESQUISA EM ENSINO DE CIÊNCIAS, 3, 2003, Bauru: Atas...

CARDOSO, S. O. O.; DICKMAN, A. G. Simulação computacional aliada à teoria da aprendizagem significativa: uma ferramenta para ensino e aprendizagem do efeito fotoelétrico. Caderno Brasileiro de Ensino de Física, v. 29, p. 891-934, outubro 2012.

DICKMAN, A. G.; CARDOSO, S. O. O. Simulação computacional aliada à teoria da aprendizagem significativa: uma ferramenta para ensino e aprendizagem do efeito fotoelétrico. Caderno Brasileiro de Ensino de Física, v. 29, n. 2, p. 891-934, out. 2012.

HECLER, V.; SARAIVA, M. F. O.; FILHO, K. S. O. Uso de simuladores, imagens e animações como ferramentas auxiliares no ensino/aprendizagem de óptica. Revista Brasileira de Ensino de Física, v. 29, n. 2, p. 267-273, fev. 2007.

HOLEC, S.; PFEFFEROVÁ, M. S.; RAGANOVÁ, J. Computer Simulations in Mechanics at the Secondary School. Informatics in Education, v. 3, n. 2, p. 229-238, ago. 2004.

MACÊDO, J. A. D. et al. Levantamento das abordagens e tendências dos trabalhos sobre as Tecnologias de Informação e Comunicação apresentados no XIX Simpósio Nacional de Ensino de Física. Caderno Brasileiro de Ensino de Física, v. 31, n. 1, p. 167-197, abr. 2014.

MACÊDO, J. A. D.; DICKMAN, A. G.; ANDRADE, I. S. F. D. Simulações computacionais como ferramentas para o ensino de conceitos básicos de eletricidade. Caderno Brasileiro de Ensino de Física, v. 29, p. 562-613, set. 2012.

MEDEIROS, C. F.; MEDEIROS, A. Possibilidades e limitações das simulações computacionais no ensino da física. Revista Brasileira de Ensino de Física, v. 24, n. 2, p. 77 86, jun. 2002. 
NARDI, R.; MACHADO, D. I. Construção e validação de um sistema hipermídia para o ensino de física moderna. Revista Electrónica de Enseñanza de las Ciencias, v. 6, n. 1, p. 90-116, 2007.

OSTERMANN, F.; MOREIRA, M. A. Uma revisão bibliográfica sobre a área de pesquisa "física moderna e contemporânea no ensino médio. Investigações em Ensino de Ciências, v. 5, n. 1, p. 23-48, jan. 2000.

PEREIRA, A. P. D.; JUNIOR, P. L. Impl icações da perspectiva de Wertsch para a interpretação da teoria de Vygotsky no ensino de Física. Caderno Brasileiro de Ensino de Física, v. 31, n. 3, p. 518-535, dez. 2014.

SOUZA, A. M. D.; NAZARÉ, T. S. D. A utilização de um programa de computador para simulações de experimentos de óptica para promover o aprendizado de ciências exatas. Física na Escola, v. 13, p. 30-31, mai. 2012.

TERRAZZAN, E. A. Perspectivas para a inserção da física moderna na escola média. 1994. Tese (Doutorado) - Universidade de São Paulo, São Paulo-SP.

VALENTE, J. A. O Computador na Sociedade do Conhecimento. (Org.) VALENTE, J. A. Campinas: UNICAMP/NIED, 1999.

VEIT, E. Â.; ARAÚJO, I. S. Modelagem computacional no ensino de física. In:ENCONTRO DE FÍSICOS DO NORTE E NORDESTE, Maceió, 2005.

VYGOTSKY, L. S. A formação social da mente. São Paulo: Martins Fontes, 1991.

WIEMAN, C. E. et al. Teaching Physics Using PhET Simulations. The Physics Teacher, v. 48, p. 225-227, abr. 2010.

WILSON, J. M.; REDISH, E. F. Using computers in teaching physics. Physics Today, v. 42, n. 34, p. 34-41, jan. 1989. 